\title{
PHYTOCHEMICAL STUDY AND IN VITRO ANTIOXIDANT ACTIVITIES OF HAMMADA SCOPARIA EXTRACTS FROM SOUTHEASTERN ALGERIA
}

\author{
BENKHERARA SALAH ${ }^{1,2}$, BORDJIBA $0^{2}$ \\ ${ }^{1}$ Department of Biology, Faculty of Sciences of Nature and Life and Earth Sciences, University of Ghardaia, Algeria. ${ }^{2}$ Laboratory of Plant \\ Biology and Environment, Faculty of Sciences, BADJI Mokhtar University, Annaba, Algeria. \\ Email: salahbn07@yahoo.fr \\ Received: 02 May 2018, Revised and Accepted: 13 June 2018
}

ABSTRACT

Objective: This study was carried out to determine the phytochemical constituents and to evaluate the antioxidant potential of the aerial part extracts of Hammada scoparia (Pomel) Iljin to validate the medicinal potential of this Algerian plant species.

Methods: Crude extracts were prepared by cold maceration with absolute methanol and distilled water. Preliminary phytochemical screening is carried out to detect the presence of the major secondary metabolites using qualitative characterization methods. Quantitative estimation of total phenols, total flavonoids, flavanols, flavonols, and condensed tannins contents is performed using gallic acid, rutin, catechin, and quercetin as standards. In vitro antioxidant activity was evaluated by the free radical scavenging activity by 2,2-diphenyl-1-picrylhydrazyl (DPPH), trolox equivalent antioxidant capacity by scavenging of 2,2'-azinobis-(3-ethylbenzothiazoline-6-sulfonic acid) (ABTS) radical cation assay, and the ferric reducing power assay (ferric reducing antioxidant power).

Results: Phytochemical screening showed the presence of alkaloids, flavonoids, tannins, terpenes and sterols, saponins, and anthocyanins. Total phenols were present more in aqueous crude extract (ACE) with $336.756 \pm 0.855 \mathrm{mg}$ gallic acid equivalent/g DM. Total flavonoids and flavonols were more abundant in methanolic crude extract (MCE) than ACE. However, condensed tannins and flavanols were present less in MCE with only $0.958 \pm 0.052$ and $4.547 \pm 0.055 \mathrm{mg}$ CE/g DM, respectively. The ACE of this plant species had greater antioxidant activity than the other extract by DPPH and ABTS assays (35.823 \pm 0.129 and $51.323 \pm 0.394 \mathrm{mg}$ trolox equivalent/g DM). The better ferric reducing power (2060.535 $\pm 2.566 \mathrm{mM} \mathrm{Fe} / \mathrm{g}$ DM) was also recorded with the same extract.

Conclusion: ACE of aerial part of H. scoparia (Pomel) Iljin showed a high amount of secondary metabolites. The obtained results confirmed that the extracting solvent influenced the antioxidant property estimations of this plant. Hence, the ACE can be further exploited further for in vitro and in vivo research work.

Keywords: Phytochemical study, Antioxidant activity, Crude extract, Hammada scoparia, Southeastern Algeria.

(C) 2018 The Authors. Published by Innovare Academic Sciences Pvt Ltd. This is an open access article under the CC BY license (http://creativecommons. org/licenses/by/4. 0/) DOI: http://dx.doi.org/10.22159/ajpcr.2018.v11i10.27067

\section{INTRODUCTION}

The part of unexplored plant species in both chemistry and biology is still immense. This offers the hope of discovering treatments for still devastating diseases and offering inexpensive therapeutic alternatives with fewer side effects.

Oxidative stress has actually been described as a crucial etiological factor involved in various chronic human diseases such as cancer, cardiovascular and neurodegenerative diseases, inflammation, diabetes, and aging [1]. These oxidative damages are achieved by the attack of free radicals on various biomolecules, in particular proteins, lipids, and DNA, finally resulting in the degradation and death of cells [2]. Several synthetic antioxidants such as butylated hydroxyanisole and butylated hydroxytoluene may be inadequate for chronic human consumption because many recent studies have mentioned their potential toxic properties for human health and the environment [3]. Therefore, the interest for normal (non-toxic) antioxidants, especially of plant origin, has increased considerably in recent years.

Nowadays, the secondary metabolites of medicinal plants are the biochemical compounds that are used to develop drugs [4]. Current studies on these biochemical compounds obviously focus on the exploration of their pharmacological activities [5,6]. The Algerian flora is full of several plant species that have not yet been studied but with real pharmacological properties [7-9]. The total and perfect control of the various properties of these plants, which involves the determination of all the physicochemical groups capable of generating one or more pharmacological effects, is today a goal that occupies a first order [10]. For this reason, we are interested in performing a preliminary phytochemical study of Hammada scoparia (Pomel) Iljin in the region of Biskra in Southeastern Algeria and evaluating the antioxidant activity of its crude extracts. This plant species belongs to the Chenopodiaceae family, which is widely distributed in temperate salt habitats, especially in the coastal regions of the Mediterranean Sea, arid steppes, and deserts [11].

This species is used in traditional medicine to treat eye disorders [12,13] and to reduce scars [14], for its larvicidal activities [15,16], anticancer, antiplasmodial [17,18], anti molluscicide [19], and antileukemic [20]. However, relatively there are not many researches that have been published on his phytochemistry.

For this, we have planned to carry out, on the hand, a phytochemical study that includes phytochemical tests for the detection of major compounds of secondary metabolism, preparation of crude extracts (methanolic and aqueous), and content determination assays of total polyphenols, total flavonoids, flavanols, flavonols, and condensed tannins; on the other hand, the evaluation of the antioxidant activity of the aerial part of this species uses three methods: 2,2-diphenyl-1picrylhydrazyl technique (DPPH) or free radical scavenging activity), free radical scavenging test by 2,2'-azinobis-(3-ethylbenzothiazoline-6sulfonic acid (ABTS), or trolox equivalent antioxidant capacity (TEAC) antioxidant capacity in trolox equivalent and that of ferric reducing antioxidant power (FRAP). 


\section{MATERIALS AND METHODS}

\section{Plant material}

The plant material consists of the aerial part of a halophytic plant of the Chenopodiaceae family (Remth) or H. scoparia (Pomel) Iljin (=Arthrophytum scoparium (PomelIljin=Haloxylon articulatum ssp. scoparium [Pomel] Batt.=Haloxylon scoparium Pomel $=H$. articulatum [Cav.] Bunge) [21-23]. This plant species is kindly identified by Professor Gerard De Belair, Faculty of Sciences, Annaba University. A voucher specimen was deposited at the Herbarium of the Department of Biology, Faculty of Sciences, Annaba University. It is a plant originating from North Africa and the Middle East [24-26].

Samples were taken early in the morning in August 2015 from Biskra in Southeastern Algeria. These samples were deposited in the Laboratory of Plant Biology and Environment, Faculty of Sciences of BADJI Mokhtar, Annaba University.

\section{Methods}

\section{Phytochemical screening}

Phytochemical screening tests consist of detecting different families of secondary metabolites existing in the aerial part of this plant with qualitative characterization reactions. These reactions are based on precipitating or staining phenomena with reagents specific to each family of compounds [27]. These tests are performed according to methods described in the researches of Ronchetti and Russo [28], Hegnauer [29], Wagner [30], and Békro et al. [31] and the works of Solfo [32], Rizk et al. [33], and Bouquet [34].

\section{Preparation of plant extracts}

The aqueous and methanolic crude extractions are carried out in triplicate.

\section{Methanolic Crude Extract (MCE)}

The MCE is prepared according to the method of Falleh et al. [35]: $2.5 \mathrm{~g}$ of plant drug is macerated in $25 \mathrm{ml}$ of absolute methanol with magnetic stirring for $30 \mathrm{~min}$. After filtration, the solvent is evaporated to dryness under reduced pressure at $50^{\circ} \mathrm{C}$ using a rotary evaporator (Buchi Rotavapor R-200). The obtained extract is then stored at $4^{\circ} \mathrm{C}$

\section{Aqueous crude extract (ACE)}

According to Majhenic et al. [36], $10 \mathrm{~g}$ of powder of aerial part dissolved in $150 \mathrm{ml}$ of distilled water was heated at reflux for $2 \mathrm{~h}$, after cold filtration; this filtrate was then evaporated to dryness under reduced pressure at $65^{\circ} \mathrm{C}$ using a rotary evaporator (Buchi Rotavapor R-200). The obtained extract is also stored at $4^{\circ} \mathrm{C}$

\section{Quantitative determination assays}

\section{Total phenolic content}

Total polyphenol content is determined spectrophotometrically using Folin-Ciocalteu reagent. The maximum absorption is between 700 and $760 \mathrm{~nm}$ and is proportional to the amount of polyphenols present in plant extracts [37]. Total polyphenol content is determined according to the method described by Singleton and Rossi [38]: A volume of $0.25 \mathrm{ml}$ of the plant extract is mixed with $1.25 \mathrm{ml}$ of Folin-Ciocalteu reagent (diluted 10 times in water). After stirring and incubation for $5 \mathrm{~min}, 1 \mathrm{ml}$ of sodium carbonate solution $(7.5 \%)$ is added. The mixture is allowed to stand in the dark at room temperature for 90 min with intermittent agitation.

The absorbance of the resulting solution is measured at $765 \mathrm{~nm}$ against a blank. The total polyphenol content is expressed in milligram of gallic acid equivalent per gram of dry matter (mg GAE/g DM). A calibration curve is carried out in parallel under the same experimental conditions using gallic acid [39] as a positive control.

\section{Total flavonoids content}

Flavonoid contents are estimated according to the aluminum chloride colorimetric method of Djeridane et al. [40]. Briefly, $1 \mathrm{~mL}$ of diluted extract is mixed with $1 \mathrm{ml}$ of $2 \% \mathrm{AlCl}_{3}$ methanolic solution. After incubation at room temperature for $15 \mathrm{~min}$, the absorbance is measured at $430 \mathrm{~nm}$. Flavonoid contents are calculated from a calibration curve of rutin and expressed as milligrams of rutin equivalent per gram of dry matter (mg $\mathrm{RE} / \mathrm{g} \mathrm{DM})$. The results are presented as means of three determinations.

\section{Total flavanols content}

Total flavanol contents in the methanolic and aqueous extracts are estimated using the DMACA-protocol of Li et al. [41] with slight modifications. To $200 \mu \mathrm{l}$ of sample (or standard) are mixed with $1.5 \mathrm{ml}$ of $0.1 \%$ (DMACA in HCL [1M]). The absorption at $640 \mathrm{~nm}$ is read after 15 min of incubation at room temperature. Total flavanol contents are calculated from a calibration curve of catechin and expressed as milligrams of catechin equivalent per gram of dry matter (mg CE/g DM). The results are presented as means of triplicate analyses.

\section{Total flavonol content}

Total flavonols in the plant extracts are estimated using the method of Kumaran and Kumaran [42]. To $2.0 \mathrm{ml}$ of sample (or standard), $2.0 \mathrm{ml}$ of $2 \%\left(\mathrm{AlCl}_{3}\right.$ in ethanol $)$ and $3.0 \mathrm{ml}(50 \mathrm{~g} / \mathrm{l})$ sodium acetate solutions are added. The absorption at $440 \mathrm{~nm}$ is read after $2.5 \mathrm{~h}$ at $20^{\circ} \mathrm{C}$. Total flavonol contents are calculated from a calibration curve of quercetin and expressed as milligrams of quercetin equivalent per gram of dry matter (mg QE/g DM). The results are presented as means of three determinations.

\section{Total condensed tannin content}

The tannin contents or proanthocyanidin is determined by the method of Broadhurst and Jones [43] with slight modifications, using catechin as a reference compound. A volume of $400 \mu \mathrm{l}$ of extract is added to $3 \mathrm{~mL}$ of a solution of vanillin ( $4 \%$ in methanol) and $1.5 \mathrm{~mL}$ of concentrated hydrochloric acid. After $15 \mathrm{~min}$ of incubation, the absorbance is read at $500 \mathrm{~nm}$. The total condensed tannin contents are expressed as milligrams of catechin equivalent per gram of dry matter (mg CE/g DM). The results are presented in triplicate.

\section{Antioxidant activity}

The antioxidant activity is evaluated by the free radical scavenging activity by DPPH, total antioxidant activity (total antioxidant activity [TAA]) by scavenging of ABTS radical cation assay, and the ferric reducing power assay.

\section{Free radical scavenging activity}

DPPH is a stable free radical with purplish color that absorbs at $517 \mathrm{~nm}$. In the presence of antiradical compounds, the DPPH radical is reduced and changes color turning yellow. Measured absorbances serve to calculate the percentage of inhibition of the DPPH radical, which is proportional to the antiradical power of the sample [44]. This method is based on measuring the ability of antioxidants to scavenge the DPPH radical. The percentage of scavenging of radicals is calculated according to the following equation: [(A1-A2)/A1] $\times 100$.

A1: Absorbance of control (DPPH solution without extract). A2: Absorbance in the presence of extract.

The effect of each extract on DPPH is measured by the procedure described by Sanchez-Moreno et al. [45] and Anton et al. [46]: A volume of $50 \mu \mathrm{l}$ of different concentrations of each extract is added to $1.95 \mathrm{ml}$ of the methanolic solution of DPPH $60 \mu \mathrm{M}(0.025 \mathrm{~g} / \mathrm{L})$ freshly prepared. Concerning the negative control, $50 \mu$ l of methanol is mixed with $1.95 \mathrm{ml}$ of methanolic solution of DPPH. After incubation in the dark and at room temperature for $30 \mathrm{~min}$, the reading of absorbances is carried out at $515 \mathrm{~nm}$ against a blank for each concentration which contains $50 \mu \mathrm{l}$ of each concentration of the extract and $1.95 \mathrm{ml}$ of methanol.

The TAA in crude extracts is determined according to the TEAC assay following the original analytical procedure described by Re et al. [47] 
with slight modifications. ABTS radical cation $\left(\mathrm{ABTS}^{+}\right)$is produced by reacting a $7 \mathrm{mM}$ ABTS stock solution with $2.45 \mathrm{mM}$ potassium persulfate (final concentration). The mixture is allowed to stand in the dark at room temperature for $12-16 \mathrm{~h}$ before use. The radical was stable in this form for more than 2 days when protected from light and stored at room temperature. For the study, the $\mathrm{ABTS}^{+}$stock solution is diluted with ethanol to an absorbance of $0.70 \pm 0.02$ at $734 \mathrm{~nm}$ and equilibrated at $30^{\circ} \mathrm{C}$. Sample solutions of $30 \mathrm{~mL}$ (or standard) are mixed with $\mathrm{ABTS}^{+}$solution $3 \mathrm{ml}$. Absorbance readings are taken at $30^{\circ} \mathrm{C}$ exactly 6 min after initial mixing. Appropriate solvent blank is obtained by mixing $30 \mathrm{~mL}$ of absolute ethanol with $3 \mathrm{~mL}$ of $\mathrm{ABTS}^{+}$solution and monitored its absorbance at $6 \mathrm{~min}$. All determinations are carried out in triplicate. The $\mathrm{ABTS}^{+}$scavenging effect (\% inhibition) is calculated by the following equation:

$\%$ Inhibition= $\left[\left(\mathrm{A}_{734 \mathrm{blank}}-\mathrm{A}_{734 \mathrm{sample}}\right) / \mathrm{A}_{734 \text { blank }}\right] \times 100$, where $\mathrm{A}_{734 \mathrm{blank}}$ and $\mathrm{A}_{734 \mathrm{sample}}$ are the absorbances of $\mathrm{ABTS}^{+}$solution at $734 \mathrm{~nm}$ before and after the sample addition. Calibration is performed, as described previously, with trolox stock solutions. Results are expressed as milligram trolox equivalent per milligram of dry plant matter.

\section{Ferric reducing power assay}

The reducing power of an extract is associated with its antiradical power. This technique allows to measure the capacity of extracts to reduce the ferric iron $\left(\mathrm{Fe}^{+3}\right)$ present in the $\mathrm{K}_{3} \mathrm{Fe}(\mathrm{CN})_{6}$ complex to ferrous iron $\left(\mathrm{Fe}^{+2}\right)$ [48] or the reduction of ferric tripyridyltriazine [Fe(III)TPTZ] in ferrous tripyridyltriazine [Fe(II)-TPTZ] at low $\mathrm{pH}$, and this is a simple and reproducible technique [49]. The complex Fe(II)-TPTZ has an intensive blue color and can be monitored at $593 \mathrm{~nm}$ [50]. The FRAP reagent is freshly prepared by mixing $10 \mathrm{~V}$ of acetate buffer $(300 \mathrm{mM}$, $\mathrm{pH}$ 3.6), $1 \mathrm{~V}$ of TPTZ solution ( $10 \mathrm{mM}$ TPTZ in $40 \mathrm{mM} / \mathrm{HCl}$ ), and $1 \mathrm{~V}$ of $\left.\mathrm{FeCl}_{3} \cdot 6 \mathrm{H}_{2} 0,20 \mathrm{mM}\right)$ with a ratio of $(10 \mathrm{~V} / 1 \mathrm{~V} / 1 \mathrm{~V})$.

$1.8 \mathrm{ml}$ of FRAP reagent, $180 \mu \mathrm{l}$ of distilled water, and $60 \mu \mathrm{l}$ of plant extract are mixed and incubated at $37^{\circ} \mathrm{C}$ for $30 \mathrm{~min}$. Absorbance is measured at $593 \mathrm{~nm}$, using the FRAP solution as a blank. The antioxidant potential of extracts is determined from a standard curve plotted using the linear regression equation of $\mathrm{FeSO}_{4} \cdot 7 \mathrm{H}_{2} \mathrm{O}$. Results are expressed in $\mathrm{mmolFe}^{+2} / \mathrm{g}$ of dry plant matter.

\section{Statistical analysis}

Data are analyzed using Microsoft Excel packaged in Microsoft Office 2010 (Microsoft Corporation, USA) and reported as mean \pm standard deviation of triplicate determination.

\section{RESULTS AND DISCUSSION}

The results of phytochemical screening tests of the different phytochemical groups of aerial part of $H$. scoparia (Pomel) Iljin are grouped in Table 1.

\section{Table 1: Results of characterization reactions of phytochemical groups}

\begin{tabular}{lll}
\hline Phytochemical groups & & Characterization reactions \\
\hline Flavonoïds & + & Positive reaction \\
Tannins & + & Positive \\
Saponins & + & Positive \\
Cardinolids & - & Négative \\
Anthocyanins & + & Positive \\
Leucoanthocyanins & - & Négative \\
Terpenes and sterols & + & Positive \\
Alcaloïds & + & Positive \\
\hline
\end{tabular}

The preliminary biochemical tests of different compounds of the aerial part allowed to appreciate the biochemical quality of this plant species. In other words, these tests revealed the presence of six major compounds of secondary metabolism (alkaloids, flavonoids, tannins, saponins, anthocyanins, and terpenes and sterols) and the absence of two other important compounds: Cardinolids and leucoanthocyanins. The presence of these secondary metabolites suggests that the plant might be of medicinal importance. As reported in earlier studies, flavonoids and phenolic compounds exhibited a wide range of biological activities such as antioxidant and lipid peroxidation inhibition properties [51,52].

The aqueous and methanolic crude extractions of the aerial part of H. scoparia allowed to calculate the yield of each extract (Table 2).

From these results (Tables 1 and 2), it seems clear that the yield of ACE $(44.44 \%)$ is higher than that of crude methanolic extract $(20.66 \%)$. These results indicate that the groups of metabolites existing in the aerial part of this plant are more extractable with water and have more affinity for water than for methanol.

By comparison with the results of phytochemical screening tests which are carried out largely on filtrates obtained by infusion, decoction, or maceration and which have demonstrated the presence of flavonoids, tannins, anthocyanins, and others, the obtained yields confirm the intensities of the results of phytochemical tests, and therefore, it can be said that the crude extract of aerial part consists essentially of polyphenols.

These results are more or less comparable with those obtained in the works of Mezghani-Jarraya et al. [19] with a yield equal to $15.10 \%$ of methanolic extract of the aerial part of H. scoparia of Sfax in Tunisia and completely different with the results of Bouaziz et al. [17] where the yield of MCE is about $6.15 \%$ of the same plant species in the same region of Sfax in Tunisia. On the other hand, and by comparison with the obtained data in the works of Bourogaa et al. [53] realized on the same species H. scoparia (Pomel) Iljin in the southern region of Tunisia (the yield of ACE is only about $11 \%$ ), a major difference is recorded with a very high yield of $44.44 \%$ in ACE of the aerial part of our plant species in southeastern Algeria which was the principal subject of our experimental study. However, this low yield (11\% in aqueous extract) is also reported in the results of Taîr et al. [54] with the same plant species in the region of Naâma in northwestern Algeria.

Total polyphenols, flavonoid, flavanol, flavonol, and condensed tannin contents

Based on the absorbance value of the extract solution and by comparison with the standard solution, the results of the colorimetric analysis of the total polyphenols, flavonoids, flavonols, flavanols, and condensed tannins are represented in Table 2 .

The results are expressed in milligram equivalent (standard) per gram of dry plant matter (mg standard E/g DM), using the equation of the linear regression of the calibration curve plotted from the corresponding standard (gallic acid, rutin, quercetin, and catechin, respectively).

Phenolic compounds are ubiquitous secondary metabolites in plants. They are known to have antioxidant activities. The activity of plant extracts is probably due to these compounds $[55,56]$. The obtained results show us a very high content of total polyphenols equal to $336.756 \pm 0.855 \mathrm{mg}$ GAE/g DM in the ACE of the aerial part of $H$. scoparia (Pomel) Iljin and 228.582 $\pm 0.689 \mathrm{mg}$ GAE/g DM in crude methanol extract.

The colorimetric assays of the other families or classes of secondary metabolites allowed us to record more or less considerable contents in the crude methanolic extract ranging from $0.958 \pm 0.052 \mathrm{mg} \mathrm{CE} / \mathrm{g}$ $\mathrm{DM}$ to $17.056 \pm 0.108 \mathrm{mg} \mathrm{RE} / \mathrm{g} \mathrm{DM}$ of tannins, flavonols, flavanols, and total flavonoids, respectively, and from $2.576 \pm 0.112 \mathrm{mg}$ CE/g DM to $12.955 \pm 0.117 \mathrm{mg} \mathrm{RE} / \mathrm{g}$ DM in the ACE. These contents are for the most part very high in the aqueous crude extract. An exception is recorded with 17,056 mg RE/ g DM of total flavonoids in the crude methanol extract, probably due to the presence of anthocyanidols which can be obtained either from flavonols (by reduction) or by oxidation of 
Table 2: Secondary metabolites contents in aerial part extracts of $\boldsymbol{H}$. scoparia

\begin{tabular}{lllllll}
\hline $\begin{array}{l}\text { Aerial part } \\
\text { extracts }\end{array}$ & Yield (\%) & \multicolumn{4}{l}{ Compound contents } & \multicolumn{2}{l}{$l$} \\
\cline { 2 - 7 } & & $\begin{array}{l}\text { Total phenolic } \\
\text { (mg GAE/g DM) }\end{array}$ & $\begin{array}{l}\text { Total flavonoids } \\
\text { (mg RE/g DM) }\end{array}$ & $\begin{array}{l}\text { Total flavanols } \\
\text { (mg CE/g DM) }\end{array}$ & $\begin{array}{l}\text { Total flavonols } \\
\text { (mg QE/g DM) }\end{array}$ & $\begin{array}{l}\text { Total condensed tannins } \\
\text { (mg CE/g DM) }\end{array}$ \\
\hline MCE & 20.66 & $228.582 \pm 0.689$ & $17.056 \pm 0.108$ & $4.547 \pm 0.055$ & $6.197 \pm 0.079$ & $0.958 \pm 0.052$ \\
ACE & 44.44 & $336.756 \pm 0.855$ & $12.955 \pm 0.117$ & $7.166 \pm 0.158$ & $16.580 \pm 0.342$ & $2.576 \pm 0.112$ \\
\hline
\end{tabular}

MCE: Methanolic crude extract, ACE: Aqueous crude extract, GAE: Gallic acid equivalent, H. scoparia: Hammada scoparia, RE: Rutin equivalent, CE: Catechin equivalent, QE: Quercetin equivalent

flavanols. Thus, it can be concluded that it will be possible with absolute methanol to extract and obtain a better yield of anthocyanidols.

A similarity is recorded by comparison with previous works realized by Allaoui et al. [57] on the aerial part of the same plant species which was the subject of our study, but in the region of Ghardaia in the Algerian northern Sahara, a very high levels of total polyphenols $(397.743 \mathrm{mg}$ $\mathrm{GAE} / \mathrm{g}$ extract) and flavonoids (82.835 mg QE/g extract) are obtained in the ethyl acetate extract (extraction solvent of lower polarity compared to that of water and methanol with which we have prepared our plant extracts). This confirms the richness of this plant on polyphenols and also the influence of the extraction solvent on secondary metabolite contents. In the same context, our results are completely different with those obtained by Tahar et al. [58] on crude extracts prepared with solvents of increasing polarity (ethyl acetate, dichloromethane, and n-butanol) of the aerial part of $H$. scoparia of Laghouat in Southern Algeria; very low levels of total polyphenols, flavonoids, and tannins are recorded ranging from 2.416 to $18.666 \mathrm{mg} \mathrm{GAE} / \mathrm{g} \mathrm{DM}, 0.128-0.305 \mathrm{mg}$ $\mathrm{QE} / \mathrm{g} \mathrm{DM}$, and from 0.315 to $2.862 \mathrm{mg} \mathrm{CE} / \mathrm{g} \mathrm{DM}$, respectively.

Concerning flavanols, flavonols, and tannins and by comparison of the different contents in the MCE and ACE, we can show that the values depend strongly on the polarity of the solvent. These values confirm, on the hand, the intensities of the results of phytochemical screening tests and, on the other hand, justify the high extractability of polar solvents and the high affinity of polyphenol compounds for solvents with increasing polarities. Thus, these results of quantification tests or assays with those of qualitative tests of the phytochemical screening show us the superior biochemical quality of the studied plant species.

This recorded difference in the yield of MCE or ACE in the aerial part of our species $H$. scoparia (Pomel) Iljin or even underground plants of the same species in different regions; and also in the contents of total polyphenols, flavonoids, flavanols, flavonols and condensed tannins, it can be attributed to operating conditions of the experiment (polar or non-polar extraction solvent, quantity of plant matter, dry or fresh, temperature and extraction time, and even extraction techniques) [59] and to several factors such as:

- Climatic and environmental factors: The geographical area, drought, soil, and microclimate type and also the bioclimatic stages [60], aggression, and diseases

- Genetic heritage, period and time of harvest, and the stage of development of the plant

- Quantification method or assay that can certainly influence the estimation of the total polyphenol content or any other active principle or secondary metabolite [61]

DPPH, ABTS radical scavenging activity, and FRAP reducing ability The results of the antioxidant activity of plant samples vary according to the nature of the extraction solvent, its polarity, and the followed analysis methods. Recent studies have shown that there is no universal method to evaluate the antioxidant activity quantitatively and accurately [62]. Therefore, the antioxidant activity of plants is evaluated using several methods. Previous studies by Schlesier et al. [63] showed that, when analyzing the antioxidant activity, it is preferable to use at least two methods. In their experiments, they used six methods to assess the antioxidant activity of tea and fruit juices: DPPH, ABTS, total radical-trapping antioxidant parameter assay, $\mathrm{N}, \mathrm{N}$-dimethyl- p-phenylenediamine assay, photo chemiluminescence assay, and ferric reducing ability of plasma assay. Among the samples analyzed, blackcurrant juice showed the greatest antioxidant activity by all the methods, but the results of the other three samples (tea, apple juice, and tomato juice) varied depending on the used method.

In this study, the evaluation of the antioxidant activity of the aerial part extracts of $H$. scoparia (Pomel) Iljin harvested in Southeastern Algeria is done using three different methods: DPPH, ABTS, and FRAP. These methods are distinguished by their mechanism of action and would be complementary to the study of the antioxidant potential of plants (Table 3).

The free radical scavenging activity is investigated using the stable radical DPPH test. We measured the capacity of extracts to scavenge the free radical DPPH causing a change of the initial violet solution to a yellow color. This is due to the formation of diphenyl picrylhydrazine by donation of hydrogen atom or an electron [64]. In our study, the scavenging effect of crude extracts showed a dose-dependent activity that can be evaluated in milligram trolox equivalent per gram of dry plant matter.

Proton radical scavenging is an important attribute of antioxidants. ABTS, a protonated radical, has characteristic absorbance maxima at $734 \mathrm{~nm}$ which decreases with the scavenging of the proton radicals [65]. The aerial part extracts of this plant species are effective scavengers of the ABTS radical. The final TEAC values of the antioxidant compounds are calculated by comparing $\mathrm{ABTS}^{+}$decolorzation with trolox, which gives a useful indication of the antioxidant potential of the plant extracts (expressed in mg trolox equivalent/g of dry plant matter).

The antioxidant activity of the ACE is higher than the MCE with $35.823 \pm 0.129$ and $29.955 \pm 0.918 \mathrm{mg}$ trolox equivalent/g DM for DPPH and $51.323 \pm 0.394$ and $40.506 \pm 0.110 \mathrm{mg}$ trolox equivalent/g DM for ABTS respectively. The scavenging of the ABTS radical by the extracts is found to be much higher than that of DPPH radical. Factors like stereoselectivity of the radicals or the solubility of the extract in different testing systems have been reported to affect the capacity of extracts to react and quench different radicals [66]. Wang et al. [67] found that some compounds which have ABTS scavenging activity did not show DPPH scavenging activity. In this study, the extracts showed strong scavenging activities against DPPH and ABTS radicals. This further showed the capability of the extracts to scavenge different free radicals in different systems, indicating that they may be useful therapeutic agents for treating radical-related pathological damage.

With the FRAP method, the antioxidant potential of our extracts is estimated from their ability to reduce TPTZ-Fe(III) complex to TPTZFe(II). The aqueous extract had a very high iron reducing power and the greatest antioxidant activity (2060.535 \pm 2.566 against only $\left.981.802 \pm 1.192 \mathrm{mM} \mathrm{Fe}^{+2} / \mathrm{g} \mathrm{DM}\right)$. This result can be attributed to the higher content of phenolic compounds of the aerial part extracts and in particular to the aqueous extract. Non-enzymatic antioxidants such as polyphenols or phenolic compounds presence may be the reason for antioxidant activity [68]. This activity is believed to be mainly due to their redox properties [69], which plays an important role in adsorbing and neutralizing free radicals, quenching singlet and triplet oxygen, or decomposing peroxides. 
Table 3: Antioxidant activity of $H$. scoparia extracts using DPPH, ABTS, and FRAP methods

\begin{tabular}{llll}
\hline Aerial part extracts & \multicolumn{3}{l}{ Antioxidant activity assays } \\
\cline { 2 - 4 } & DPPH (mg trolox E/g DM) & TAA (ABTS) (mg trolox E/g DM) & FRAP (mM Fe $^{2+} / \mathbf{D M )}$ \\
\hline MCE & $29.955 \pm 0.918$ & $40.506 \pm 0.110$ & $981.802 \pm 1.192$ \\
ACE & $35.823 \pm 0.129$ & $51.323 \pm 0.394$ & $2060.535 \pm 2.566$ \\
\hline
\end{tabular}

MCE: Methanolic crude extract, TAA: Total antioxidant activity, ACE: Aqueous crude extract, DPPH: 2,2-diphenyl-1-picrylhydrazyl, ABTS:

2,2'-azinobis-(3-ethylbenzothiazoline-6-sulfonic acid), FRAP: Ferric reducing antioxidant power, H. scoparia: Hammada scoparia

The $\mathrm{DPPH}^{+}$free radical scavenging results in this study are more or less comparable with those obtained in the works of Bourogaa et al. [53] with the ACE of the H. scoparia in Southern Tunisia. A strong antiradical activity (DPPH) like that of our plant is recorded. A similarity is recorded with the results of Bouaziz et al. [17] on the same plant species in the region of Sfax in Tunisia when the methanolic extract of the leaves is able to present a powerful antioxidant activity DPPH and ABTS. However, the dichloromethane and n-hexane (solvents of decreasing polarity) extracts showed only low antiradical power. In this same context and by comparison with previous works done by Allaoui et al. [57] on H. scoparia from Ghardaia in southern Algeria, a less powerful FRAP reducing antioxidant power than that recorded with the crude methanolic and aqueous extracts of our plant is recorded.

DPPH scavenging activities, ABTS radical scavenging, and FRAP assays of both methanolic and ACEs are very important. The obtained results of these in vitro tests gave us an idea about the relative antioxidant activity of aerial part extracts of H. scoparia (Pomel) Iljin. This study confirmed the medicinal potential of the leaves and stems of this halophytic plant species and is in agreement with the medicinal potential of Chenopodiaceae family showed by several authors $[20,54,70]$.

\section{CONCLUSION}

This study showed the presence of some secondary metabolites in aerial part and provided informative data for the traditional use of H. scoparia crude extracts. High contents of total polyphenols and strong antioxidant activity are recorded with the ACE more than MCE.

The results from this study indicate that the aerial part extracts of this plant possess antioxidant properties and could serve as free radical inhibitors or scavengers or acting possibly as primary antioxidants. These results indicate also that selective extraction of bioactive molecules from natural sources such as halophyte species, with appropriate solvents, can provide fractions with high biological activity that could be used as preservatives in food or pharmaceuticals. Again, a lot of attention is being devoted to natural sources of antioxidant materials, and the data obtained in this study might suggest a possible use of H. scoparia as a source of natural antioxidant agents.

Based on these results, H. scoparia is a potent source of new bioactive compounds. Further investigations concerning more biological activities of the parts of this plant need to be conducted.

\section{ACKNOWLEDGMENT}

The authors thank gratefully Professor Chokri MESSAOUD (National Institute of Applied Science and Technology INSAT, Tunisia) for his precious help.

\section{AUTHOR'S CONTRIBUTION}

Benkherara S. performed the experimentation as part of his Ph.D.

Benkherara S. and BORDJIBA O. prepared the manuscript, and Bordjiba O. supervised the work, evaluated the data, and corrected the manuscript for publication. All authors read and approved the final manuscript.

\section{CONFLICTS OF INTEREST}

The authors declare that they have no conflicts of interest.

\section{REFERENCES}

1. Uttara B, Singh AV, Zamboni P, Mahajan RT. Oxidative stress and neurodegenerative diseases: A review of upstream and downstream antioxidant therapeutic options. Curr Neuropharmacol 2009;7:65-74.

2. Moon JK, Shibamoto T. Antioxidant assays for plant and food components. J Agric Food Chem 2009;57:1655-66.

3. Edziri H, Mastouri M, Aouni M, Verschaeve L. Polyphenols content, antioxidant and antiviral activities of leaf extracts of Marrubium deserti growing in Tunisia. South Afr J Botany 2012;80:104-9.

4. Yadav M, Chatery S, Gupta SK, Watal G. Preliminary phytochemical screening of six medicinal plants used in traditional medicine. Int $\mathrm{J}$ Pharm Pharm Sci 2014;6:539-42.

5. Cai Y, Sun M, Corke H. Antioxidant activity of betalains from plants of the Amaranthaceae. J Agric Food Chem 2003;51:2288-94.

6. Zhang M, Hongfei J, Aiti A, Haizhou L, Chew LT, sheng L. A tree sequence alignment based tree-to-tree translation model. ACLHLT 2008;08:559-67.

7. Bnouham M, Mekhfi H, Legssyer A, Ziyyat A. Medicinal plants used in the treatment of diabetes in Morocco. Int J Diabetes Metab 2002;10:33-50.

8. González-Tejero MR, Casares-Porcel M, Sánchez-Rojas CP, RamiroGutiérrez JM, Molero-Mesa J, Pieroni A, et al. Medicinal plants in the Mediterranean area: Synthesis of the results of the project Rubia. J Ethnopharmacol 2008;116:341-57.

9. Graham JG, Quinn ML, Fabricant DS, Farnsworth NR. Plants used against cancer - an extension of the work of Jonathan Hartwell. J Ethnopharmacol 2000;73:347-77.

10. Abdelwahed A, Bouhlel I, Skandrani I, Valenti K, Kadri M, Guiraud P, et al. Study of antimutagenic and antioxidant activities of gallic acid and 1,2,3,4,6-pentagalloylglucose from Pistacia lentiscus. Confirmation by microarray expression profiling. Chem Biol Interact 2007;165:1-3.

11. Mulas M. Potentialité D'utilisation Stratégique des Plantes des Genres Atriplex et Opuntia dans la Lutte Contre la Désertification. Short and Medium, Term Priority Environmental Action Program SMAP; 2004. p. 91 .

12. Boukef MK. Les Plantes dans la Médicine Traditionnelle Tunisienne. Tunis: Agence de Coopération Culturelle et Technique; 1986. p. 82-3.

13. Le Floc'h E. Contribution à une Etude Ethnobotanique de la Flore Tunisienne. Tunis: Imprimerie Officielle de la République Tunisienne; 1983. p. 83-5

14. El-Shanawani MA. Plants Used in Saudi Traditional Medicine. Riyadh: King Saud University Press KACST; 1996. p. 126-7.

15. Ben Salah H, Jarraya R, Martin MT, Veitch NC, Grayer RJ, Simmonds MS, et al. Flavonol triglycosides from the leaves of Hammada scoparia (POMEL) ILJIN. Chem Pharm Bull (Tokyo) 2002;50:1268-70.

16. Sathiyamoorthy $\mathrm{P}$, Lugasi-Evgi H, Van-Damme P, Abu-Rabia A, Gopas J, Golan- Goldhirsh A. Larvicidal activity in desert plants of the Negev and Bedouin market plant products. Int J Pharm 1997;35:265-73.

17. Bouaziz A, Mhalla D, Zouari I, Jlaiel L, Tounsi S, Jarraya R, et al. Antibacterial and antioxidant activities of Hammada scoparia extracts and its major purified alkaloids. South Afr J Bot 2016;105:89-96.

18. Sathiyamoorthy P, Lugasi-Evgi H, Schlesinger P, Keda, I, Gopas J, Pollack Y, et al. Screening for cytotoxic and antimalarial activities in desert plants of the Negev and Bedouin market plant products. Pharm Biol 1999;37:188-95.

19. Mezghani-Jarraya R, Hammami H, Ayadi A, Damak M. Molluscicidal activity of Hammada scoparia (Pomel) iljin leaf extracts and the principal alkaloids isolated from them against Galba truncatula. Mem Inst Oswaldo Cruz 2009;104:1035-8.

20. Bourogaa E, Bertrand J, Despeaux M, Jarraya R, Fabre N, Payrastre L, et al. Hammada scoparia flavonoids and rutin kill adherent and chemoresistant leukemic cells. Leuk Res 2011;35:1093-101.

21. Zohary M. Flora Palaestina. Part I. Jerusalem: The Israel Academy of 
Science and Humanities; 1966. p. 163-4.

22. Täckholm V. Students' Flora of Egypt. $2^{\text {nd }}$ ed. Beirut: Cairo University, Cooperative Printing Company; 1974. p. 127-8.

23. Boulos L. Flora of Egypt. Vol. I. Cairo, Egypt: Al Hadara Publishing; 1999. p. 123-4

24. Maire R. Flore de l'Afrique du Nord. Vol. 8. Paris: Paul Le chevalier; 1962. p. 161-4.

25. Greuter W, Burdet MH, Long G. A Critical Inventory of the Vascular Plants of the Circum-Mediterranean Countries. Med-Checklist. Vol. 1. Genève: des Conservatoire et Jardin Botaniques de la Ville de Genève; 1984. p. 304-5

26. Jafri SM, Rateeb FB. Flora of Libya., Chenopodiaceae. Vol. 58. In: Jafri SM, El-Gadi A, editors. Tripoli: Al Faateh University, Faculty of Science; 1978. p. 88-95

27. Hagerman AE, Muller-Harvey I, Makkar HP. Quantification of Tannins in Tree Foliage. Vienna: Joint FAO/IAEA Division of Nuclear Techniques in Food and Agriculture; 2000. p. 26

28. Ronchetti F, Russo G. A new alkaloid from Rauvolfia vomitoria. Phytochemistry 1971;10:1385-88.

29. Hegnauer R. Chemotaxonomie der Pflanzen. Vol. 6. Suttgart: BikhäuserVerlag, Basel; 1973. p. 761-2.

30. Wagner H. Drogenanalyse, DünschichtchromatographischeAnalyse von Arzneidrogen. New York: Springer Verlag Berlin Heidelberg; 1983. p. 522-3

31. Békro YA, Békro JA, Boua BB, TRA BF, Ehilé EE. Ethnobotanical study and phytochemical screening of Caesalpinia benthamiana (Baill.) Herend. and Zarucchi (Caesalpiniaceae). Rev Sci Nat 2007;4:217-25.

32. Solfo RR. Etude d'une Plante Médicinale Malgache Buxus madagasca rica Bail et ses variétés. France: ORSTOM; 1973. p. 98

33. Rizk AM, Hammouda FM, Ismail SI, Hassan NM, el-Missiry MM, Ahmad FA, et al. Constituents of plants growing in Qatar. Part XIX. Flavonoids of Glossonema edule N. E. Br. Plant Foods Hum Nutr 1990;40:1-3.

34. Bouquet A. Plantes Médicinales du Congo Brazzaville. France: ORSTOM; 1972. p. 116.

35. Falleh H, Ksouri R, Chaieb K, Karray-Bouraoui N, Trabelsi N, Boulaaba M, et al. Phenolic composition of Cynara cardunculus L. Organs, and their biological activities. C R Biol 2008;331:372-9.

36. Majhenic L, Kerget MS, Knez Z. Antioxidant and antimicrobial activity of guarana seed extracts. Food Chem 2007;104:1258-68.

37. Boizot N, Charpentier J. Méthode rapide d'évaluation du contenu en composés phénoliques des oranges d'un arbre forestier. Méthodes et Outils Pour L'observation Et L'évaluation Des Milieux Forestiers, Prairiaux et Aquatiques. France: INRA 2006. p. 79-82.

38. Singleton VL, Rossi JA. Colorimetry of total phenolics with phosphomolybdic phosphotungstic acid reagents. Am J Enol Vitic 1965; $16: 144-58$

39. Li HB, Cheng KW, Wong CC, Fan KW, Chen F, Jiang Y. Evaluation of antioxidant capacity and total phenolic content of different fraction of selected microalgae. Food Chem 2007;102:771-6.

40. Djeridane A, Yousfi M, Nadjemi B, Boutassouna D, Stocker P, Vidal N. Antioxidant activity of some Algerian medicinal plants extracts containing phenolic compounds. Food Chem 2006;97:654-60.

41. Li YG, Tanner G, Larkin P. The DMACA-HCl Protocol and the threshold proanthocyanidin content for bloat safety in forage legumes. J Sci Food Agric 1996;70:89-101.

42. Kumaran A, Karunakaran RJ. In vitro antioxidant activities of methanol extracts of Phyllanthus species from India. LWT 2007;40:344-52.

43. Broadhurst RB, Jones WT. Analysis of condensed tannins using acidified vanillin. J Sci Food Agric 1978;48:788-94

44. Parejo I, Viladomat F, Bastida J, Rosas-Romero A, Saavedra G, Murcia MA, et al. Investigation of Bolivian plant extracts for their radical scavenging activity and antioxidant activity. Life Sci 2003;73:1667-81.

45. Sanchez-Moreno C, Larrauri JA, Saura-Calixto F. A procedure to measure the antiradical efficiency of polyphenols. Sci Food Agric 1998;76:270-1.

46. Anton AA, Ross KA, Lukow OM, Fulcher RG, Arntfield SD. Influence of added bean flour (Phaseolus vulgaris L.) on some physical and nutritional properties of wheat flour tortillas. Food Chem 2008;109:33-41.

47. Re R, Pellegrini N, Proteggente A, Pannala A, Yang M, Rice-Evans C. Antioxidant activity applying an improved ABTS radical cation decolourization assay. Free Rad Biol Med 1999;26:1231-37.

48. Oyaizu M. Studies on products of browning reaction prepared from glucose amine. Jpn J Nutr 1986;44:307-15.

49. Karagözler AA, Erdağ B, Emek YÇ, Uygun DA. Antioxidant activity and proline content of leaf extracts from dorystoechas hastata. Food Chem 2008;111:400-7

50. Benzie IF, Strain JJ. The ferric reducing ability of plasma (FRAP) as a measure of "antioxidant power": The FRAP assay. Anal Biochem 1996;239:70-6.

51. Arunachalam KD, Arun LB, Annamalai SK, Arunachalam AM. Biofunctionalized gold nanoparticles synthesis from Gymnema sylvestre and its preliminary anticancer activity. Int J Pharm Pharm Sci 2014;6:423-30.

52. Arunachalam KD, Annamalai SK, Arunachalam AM, Kennedy S. One step green synthesis of phytochemicals mediated gold nanoparticles from Aegle marmales for the prevention of urinary catheter infection. Int J Pharm Pharm Sci 2014;6:700-6.

53. Bourogaa E, Jarraya RM, Nciri R, Damak M, Elfeki A. Protective effects of aqueous extract of Hammada scoparia against hepatotoxicity induced by ethanol in the rat. Toxicol Ind Health 2014;30:113-22.

54. Taîr K, Kharoubi O, Taîr OA, Hellal N, Benyettou I and Aoues A. Aluminium-induced acute neurotoxicity in rats: Treatment with aqueous extract of arthrophytum (Hammada scoparia). J Acute Dis 2016;5:470-82.

55. Okudu T, Yoshida T, Hatano T. Food Phytochemicals for Cancer Prevention. $2^{\text {nd }}$ ed. Washington DC: American Chemical Society; 1994. p. 132-43.

56. Tepe B, Sokmen M, Akpulat HA, Sokmen A. Screening of the antioxidant potentials of six Salvia species from Turkey. Food Chem 2006;95:200-4.

57. Allaoui M, Cheriti A, Chebouat E, Dadamoussa B, Gherraf N. Comparative study of the antioxidant activity and phenols and flavonoids contents of the ethyl acetate extracts from two Saharan Chenopodiaceae: Haloxylon scparium and Traganum nudatum. Algerian J Arid Environ 2016;6:71-9.

58. Tahar SB, Hadj-Mahammed M, Yousfi M. Study of the antioxidant activity of phenolic extracts of Atriplex halimus and Haloxylon scoparium Pomel from Northern Sahara. Ann Sci Technol 2015;7:35-42.

59. Lee KW, Kim YJ, Lee HJ, Lee CY. Cocao has more phenolic phytochemicals and a higher antioxidant capacity than teas and red wine. Food Chem 2003;51:7292-5.

60. Atmani D. Antioxidant capacity and phenol content of selected Algerian medicinal plants. Food Chem 2009;112:303-9.

61. Miliauskas G, Venskutonis PR, Van Beek TA. Screening of radical scavenging activity of some medicinal and aromatic plant extract. Food Chem 2004;85:231-7.

62. Prior RL, Wu X, Schaich K. Standardized methods for the determination of antioxidant capacity and phenolics in foods and dietary supplements. J Agri Food Chem 2005;53:4290-302.

63. Schlesier K, Harwat M, Böhm V, Bitsch R. Assessment of antioxidant activity by using different in vitro methods. Free Radic Res 2002;36:177-87.

64. Tepe, B, Sokmen M, Akpulat HA, Sokmen A. In vitro antioxidant activities of the methanol extracts of four Helichrysum species from Turkey. Food Chem 2005;90:685-9.

65. Mathew S, Abraham TE. In vitro antioxidant activity and scavenging effects of Cinnamomum verum leaf extract assayed by different methodologies. Food Chem Toxicol 2006;44:198-206.

66. Yu L, Haley S, Perret J, Harris M, Wilson J, Qian M. Free radical scavenging properties of wheat extracts. J Agr Food Chem 2002;50:1619-24

67. Wang M, Jiangang L, Rangarajan M, Shao Y, LaVoie EJ, Huang TC, et al. Antioxidative phenolic compounds from Sage (Salvia officinalis). J Agr Food Chem 1998,46:4869-73.

68. Zahin M, Aqil F, Ahmad I. The in vitro antioxidant activity and total phenolic content of four Indian medicinal plants. Int J Pharm Pharm Sci 2009; $1: 88-95$.

69. Zheng W, Wang SY. Antioxidant activity and phenolic compounds in selected herbs. J Agric Food Chem 2001;49:5165-70

70. Louerrad Y, Haddi R, Harche MK. Study of lipid peroxidation in a medicinal plant Haloxylon scoparium Pomel. J Bioressour Valorisation 2016;1:28-33 